\title{
Serum Magnesium Measurements After Parathyroidectomy for Primary Hyperparathyroidism: Should It be Routine?
}

\author{
Peter Novodvorsky ${ }^{1,2}$ (1) - Andrew F. Lowry ${ }^{1}$ C. Beverly B. Lim ${ }^{3}$. \\ Sabapathy P. Balasubramanian ${ }^{2,3}$
}

Published online: 13 February 2020

(C) The Author(s) 2020

\begin{abstract}
Background Parathyroidectomy is the treatment of choice in primary hyperparathyroidism (PHPT). Following surgery, significant changes in bone and mineral metabolism may follow, but routine magnesium monitoring is not standard practice. The occurrence of significant clinical events linked to hypomagnesaemia in 3 patients after parathyroidectomy led to our evaluation of magnesium levels after surgery for PHPT.

Methods Serum magnesium levels before and after parathyroidectomy for PHPT were prospectively evaluated in a single centre over a year. The incidence and severity of hypomagnesaemia and its correlation with other biochemical variables were assessed.

Results A total of 138 patients underwent parathyroidectomy for PHPT. Pre-operative and day 1 post-operative serum magnesium levels were available in 57/138 (41.3\%) and 99/138 (71.7\%) patients, respectively. Serum magnesium decreased significantly after surgery (mean $\pm \mathrm{SD}$ of $0.85 \pm 0.08$ and $0.75 \pm 0.11 \mathrm{mmol} / \mathrm{L}$, respectively, $p<0.001)$. On the day after parathyroidectomy, $31 / 99(31.3 \%)$ patients had hypomagnesaemia $(<0.70 \mathrm{mmol} / \mathrm{L})$; in 3 of whom it was severe $(<0.50 \mathrm{mmol} / \mathrm{L})$. Patients with hypomagnesaemia had lower pre-operative magnesium (mean $\pm \mathrm{SD}$ of $0.78 \pm 0.06$ and $0.87 \pm 0.07 \mathrm{mmol} / \mathrm{L}, p<0.001$ ), higher pre-operative calcium [median (IQR) of $2.83(2.71-2.99)$ and $2.71(2.63-2.80) \mathrm{mmol} / \mathrm{L}, p=0.001]$ and higher post-operative calcium [median (IQR) of 2.41 (2.30-2.51) and $2.35(2.28-2.43) \mathrm{mmol} / \mathrm{L}, p=0.046]$ compared to those with normomagnesaemia. In addition, these patients demonstrated higher drop in calcium levels after surgery $(0.44 \pm 0.20$ and $0.35 \pm 0.18 \mathrm{mmol} / \mathrm{L}, p=0.033)$. Magnesium levels after surgery correlated positively with pre-operative magnesium $(r=0.561, p<0.001)$ and postoperative PTH $(r=0.210, p=0.037)$ and negatively with pre-operative adjusted calcium $(r=-0.389, p<0.001)$. Conclusions Serum magnesium decreased significantly following parathyroidectomy for PHPT and nearly a third of patients developed post-operative, mostly mild hypomagnesaemia. Whilst routine serum magnesium measurements could facilitate prompt recognition and treatment of this electrolyte disturbance, further research needs to establish the clinical importance of mild hypomagnesaemia in these clinical settings and, if indicated, to devise optimal treatment strategies.
\end{abstract}

Peter Novodvorsky

p.novodvorsky@sheffield.ac.uk

1 Department of Diabetes and Endocrinology, Sheffield Teaching Hospitals NHS Foundation Trust, Sheffield, UK

3 Department of General Surgery, Sheffield Teaching Hospitals NHS Foundation Trust, Sheffield, UK

2 Department of Oncology and Metabolism, School of Medicine and Biomedical Sciences, University of Sheffield, Beech Hill Road, S10 2RX Sheffield, UK 


\section{Introduction}

Primary hyperparathyroidism (PHPT) is characterised by excess parathyroid hormone (PTH) secretion arising mostly from one or more autonomously functioning parathyroid adenomas $(\sim 85 \%)$, parathyroid hyperplasia $(\sim 15 \%)$, and rarely $(<1 \%$ of cases) from parathyroid carcinoma [1]. PHPT has an estimated prevalence of 1:1000 [2,3] and, together with hypercalcaemia of malignancy, accounts for the majority of clinical presentations of hypercalcaemia. Parathyroidectomy represents the only opportunity for definitive cure. The immediate post-operative management focuses on establishing the success of the surgery and monitoring for symptomatic hypocalcaemia and other potentially serious complications such as bleeding, vocal cord paralysis or laryngospasm. After surgery, significant changes in bone and mineral metabolism result in rapid decline of serum PTH and normalisation or lowering of serum calcium $\left(\mathrm{Ca}^{2+}\right)$ levels.

Magnesium $\left(\mathrm{Mg}^{2+}\right)$ is the second most abundant intracellular cation and the fourth most abundant cation of the body [4]. $\mathrm{Mg}^{2+}$ is a significant component of the mineral phase of bone, plays a critical role in neuromuscular function and is a co-factor in many enzymatic reactions and biologic processes [4]. $\mathrm{Mg}^{2+}$ metabolism is intricately linked with the metabolism of $\mathrm{Ca}^{2+}$. Yet, current clinical practice and guidelines for the management of PHPT do not include routine serum $\mathrm{Mg}^{2+}$ measurements in the diagnostic workup, before or after parathyroidectomy [5]. Before the initiation of this study, 3 patients who underwent parathyroidectomy for PHPT in our centre presented with signs and symptoms of severe hypomagnesaemia several days after the surgery. These incidents led to a prospective evaluation of serum $\mathrm{Mg}^{2+}$ levels in all patients undergoing parathyroidectomy for PHPT in this centre. The relationship of serum $\mathrm{Mg}^{2+}$ levels in these patients with other commonly measured biochemical parameters of mineral and bone metabolism was also examined.

\section{Patients and methods}

This study was undertaken as a prospective service evaluation project/audit in the Department of Surgery in Sheffield Teaching Hospitals NHS Foundation Trust in Sheffield, UK, and was registered with the local Clinical Effectiveness Unit (ref. number 8272). As this was an observational study, a formal ethics application was not deemed necessary and individual patient consent was not obtained. All data collected were processed in accordance with institutional guidelines to ensure patient privacy and confidentiality.
All patients who underwent parathyroidectomy (including re-operative procedures and those who had concomitant thyroid surgery) for PHPT between 1 September 2016 and 1 September 2017 in a single tertiary endocrine surgical unit were evaluated for the availability of preoperative and day 1 post-operative serum magnesium $\left(\mathrm{Mg}^{2+}\right)$ levels. Surgery was performed either by or under the supervision of one of two consultant endocrine surgeons. All patients were admitted to hospital after surgery and had biochemical evaluation on the morning after surgery prior to being discharged. Patients with hypocalcaemia after surgery were treated with Sandocal supplements with or without alfacalcidol (1-OH cholecalciferol). Patients with low $\mathrm{Mg}^{2+}$ levels were treated with oral $\mathrm{Mg}^{2+}$ supplements $\left(\mathrm{Mg}^{2+} \mathrm{L}\right.$-aspartate powder for oral solution equivalent to $10-20 \mathrm{mmol}$ of $\mathrm{Mg}^{2+} /$ day).

Only those patients who had day 1 post-operative serum $\mathrm{Mg}^{2+}$ measured were included in subsequent analysis. Data collected at this stage also included age, date of birth, sex, type of surgery, last serum pre-operative adjusted $\mathrm{Ca}^{2+}$ and PTH, estimated glomerular filtration rate (eGFR), postoperative adjusted $\mathrm{Ca}^{2+}$ and PTH, diagnosis of osteoporosis and history of diuretic, proton pump inhibitor (PPI) or bisphosphonate use before/at the time of surgery.

The data were collected on an Excel (version 2016, Microsoft Corp., Redmond, WA, USA) spreadsheet and, after removal of patient identifiable variables, transferred to the appropriate applications for further analysis. Statistical analysis was performed with SPSS (version 23; IBM, Chicago, IL, USA). Graphs and calculation of $95 \%$ confidence intervals (CI) for correlations were completed using GraphPad Prism (version 7.03, GraphPad Software, Inc., San Diego, CA, USA). Normally distributed data were reported as mean \pm standard deviation (SD), and data which did not follow normal distribution were reported as median (interquartile range) (IQR), with corresponding 95\% CI. Data which were not normally distributed were compared with nonparametric statistical tests (MannWhitney $U$ test, Wilcoxon signed ranks test). Relationships between the variables that follow normal and non-normal distribution were examined using the Pearson's and Spearman's correlation coefficients $r$, respectively. $p<0.05$ was deemed statistically significant.

\section{Results}

Altogether 138 patients underwent parathyroidectomy for PHPT during the study period; 99/138 (71.7\%) had day 1 post-operative serum $\mathrm{Mg}^{2+}$ levels checked and were 
Table 1 Baseline characteristics of patients included in the study

\begin{tabular}{lc}
\hline Number of patients, $n$ & 99 \\
Age (years) & $61.5 \pm 15.7,22.0-85.0$ \\
Female, $n(\%)$ & $87(87.9 \%)$ \\
Type of parathyroid surgery & $46 / 99(46.5 \%)$ \\
Unilateral neck exploration, $n(\%)$ & $53 / 99(53.5 \%)$ \\
Bilateral neck exploration, $n(\%)$ & $8 / 99(8.1 \%)$ \\
Concomitant thyroid surgery, $n(\%)$ & $20(20.2 \%)$ \\
History of osteoporosis, $n(\%)$ & $2(2.0 \%)$ \\
Pre-op diuretic use, $n(\%)$ & $7(7.1 \%)$ \\
Pre-op bisphosphonate use, $n(\%)$ & $17(17.2 \%)$ \\
Pre-op PPI use, $n(\%)$ & $2.76 \pm 0.18,2.18-3.55$ \\
Pre-op adj. Ca ${ }^{2+}[2.20-2.60](\mathrm{mmol} / \mathrm{L})$ & $17.7 \pm 14.9,5.4-123.5$ \\
Pre-op PTH $[1.6-6.9](\mathrm{pmol} / \mathrm{L})$ & $0.85 \pm 0.08,0.68-1.04$ \\
Pre-op $\mathrm{Mg}^{2+}[0.70-1.00](\mathrm{mmol} / \mathrm{L})(n=57)$ & $79.3 \pm 14.2,34-90$ \\
Pre-op eGFR $\left(\mathrm{mL} / \mathrm{min} / 1.73 \mathrm{~m}^{2}\right)$ & \\
\hline
\end{tabular}

Data are displayed as mean $\pm \mathrm{SD}$, range. Values in box brackets indicate normal reference range. PPI proton pump inhibitors, $P T H$ parathyroid hormone, $e G F R$ estimated glomerular filtration rate calculated with Chronic Kidney Disease Epidemiology Collaboration (CKD-EPI) formula

included in subsequent analysis. Of these 99 patients, 57/99 (57.6\%) also had pre-operative $\mathrm{Mg}^{2+}$ levels checked. Baseline characteristics of this population are shown in Table 1. The remaining 39/138 (28.3\%) patients had either only pre-operative serum $\mathrm{Mg}^{2+}$ or no serum $\mathrm{Mg}^{2+}$ levels available at all, and were excluded from further analysis.

As expected, the pre-surgery serum adjusted $\mathrm{Ca}^{2+}$ levels reduced significantly after parathyroidectomy [median (IQR) of 2.74 (2.63-2.84) and 2.36 (2.29-2.44) mmol/L, respectively, $p<0.001]$, together with reduction in serum PTH levels [median (IQR) of 13.5 (10.2-19.8) and 2.3 (1.5-3.9) $\mathrm{pmol} / \mathrm{L}$, respectively, $p<0.001]$. Day 1 postoperative hypocalcaemia was detected in $7 / 99(7.1 \%)$ patients, one of whom had severe hypocalcaemia (adj. $\mathrm{Ca}^{2+} 1.95 \mathrm{mmol} / \mathrm{L}$ ). In those 57 patients with both pre- and day 1 post-operative $\mathrm{Mg}^{2+}$ levels recorded, a significant difference in mean $\pm \mathrm{SD}$ between pre-operative $\mathrm{Mg}^{2+}$ levels $(0.85 \pm 0.08 \mathrm{mmol} / \mathrm{L})$ and day 1 post-operative $\mathrm{Mg}^{2+}$ levels $(0.75 \pm 0.11 \mathrm{mmol} / \mathrm{L})$ was detected (mean paired difference -0.10 , 95\% CI $0.08-0.13, p<0.001)$. Only $2 / 57$ patients had mild pre-operative hypomagnesaemia: 0.68 and $0.69 \mathrm{mmol} / \mathrm{L}$, respectively. Osteoporosis was present in $20 / 57$ patients in whom pre- and day 1 postoperative $\mathrm{Mg}^{2+}$ levels were available. The reduction in $\mathrm{Mg}^{2+}$ levels in patients with osteoporosis $(0.13 \pm 0.04 \mathrm{mmol} / \mathrm{L})$ was not significantly different to the drop in $\mathrm{Mg}^{2+}$ levels in patients without osteoporosis $(0.10 \pm 0.10 \mathrm{mmol} / \mathrm{L})(p=0.143)$.

On the first day post-parathyroidectomy, $31 / 99$ (31.3\%) patients were found to have hypomagnesaemia $(<0.70 \mathrm{mmol} / \mathrm{L})$ and received $\mathrm{Mg}^{2+}$ supplementation. Of these, 3 patients had severe hypomagnesaemia $(<0.50 \mathrm{mmol} / \mathrm{L})$ and 28 had mild hypomagnesaemia (0.50-0.70 mmol/L). Day 1 post-operative $\mathrm{Mg}^{2+}$ levels in patients with osteoporosis $(0.75 \pm 0.08 \mathrm{mmol} / \mathrm{L})$ and in those without osteoporosis $(0.73 \pm 0.10 \mathrm{mmol} / \mathrm{L})$ were similar (mean difference $0.02,95 \% \mathrm{CI}-0.04$ to 0.07 , $p=0.525$ ). Table 2 shows the comparison of the group of patients with day 1 post-operative hypomagnesaemia with patients with day 1 post-operative normomagnesaemia in relation to the examined variables. Patients with day 1 post-operative hypomagnesaemia had significantly lower pre-operative $\mathrm{Mg}^{2+}$ levels $(p<0.001)$, significantly higher pre-operative $\mathrm{Ca}^{2+}$ levels $(p=0.001)$ and significantly higher post-operative adjusted $\mathrm{Ca}^{2+}$ levels $(p=0.046)$ in comparison with those with day 1 post-operative normomagnesaemia. In addition, following the surgery patients with day 1 post-operative hypomagnesaemia demonstrated higher drop in adjusted $\mathrm{Ca}^{2+}$ levels and a non-significant trend towards higher drop in PTH levels in comparison with those with day 1 post-operative normomagnesaemia (Table 2). There was no significant difference between these groups in pre- or post-operative PTH levels, pre-operative eGFR or age (Table 2).

Next, the relationship between day 1 post-operative $\mathrm{Mg}^{2+}$ levels and other available variables was examined. There was a strong positive correlation with pre-operative $\mathrm{Mg}^{2+}$ levels $(r=0.561,95 \%$ CI $0.352-0.712, p<0.001$, $n=57$ ) (Table 3 and Fig. 1); significant negative correlation with pre-operative adjusted $\mathrm{Ca}^{2+}$ levels $(r=-0.389$, $95 \%$ CI -0.548 to $-0.201, p<0.001, n=99$ ) (Table 3 and Fig. 2) and a significant positive correlation with post- 
Table 2 Comparison of the patients with day 1 post-operative hypomagnesaemia $\left(\mathrm{Mg}^{2+}<0.70 \mathrm{mmol} / \mathrm{L}\right)$ with patients with day 1 postoperative normomagnesaemia $\left(\mathrm{Mg}^{2+} \geq 0.70 \mathrm{mmol} / \mathrm{L}\right)$

\begin{tabular}{llll}
\hline & $\mathrm{Mg}^{2+}<0.70 \mathrm{mmol} / \mathrm{L}$ & $\mathrm{Mg}^{2+} \geq 0.70 \mathrm{mmol} / \mathrm{L}$ & $p$ \\
\hline Pre-op $\mathrm{Mg}^{2+}(\mathrm{mmol} / \mathrm{L})^{*}$ & $0.78 \pm 0.06$ & $0.87 \pm 0.07$ & $<\mathbf{0 . 0 0 1}$ \\
Pre-op adj. $\mathrm{Ca}^{2+}(\mathrm{mmol} / \mathrm{L})$ & $2.83(2.71-2.99)$ & $2.71(2.63-2.80)$ & $\mathbf{< 0 . 0 0 1}$ \\
Post-op adj. $\mathrm{Ca}^{2+}(\mathrm{mmol} / \mathrm{L})$ & $2.41(2.30-2.51)$ & $0.35 \pm 0.18$ & $\mathbf{0 . 0 4 6}$ \\
Pre-op/post-op adj. Ca ${ }^{2+}$ drop $(\mathrm{mmol} / \mathrm{L})^{*}$ & $0.44 \pm 0.20$ & $13.5(10.0-18.8)$ & $\mathbf{0 . 0 3 3}$ \\
Pre-op PTH $(\mathrm{pmol} / \mathrm{L})$ & $13.8(10.3-23.1)$ & $2.5(1.7-4.0)$ & 0.326 \\
Post-op PTH $(\mathrm{pmol} / \mathrm{L})$ & $2.0(1.3-3.1)$ & $12.2 \pm 6.7$ & 0.123 \\
Pre-op/post-op PTH drop $(\mathrm{pmol} / \mathrm{L})^{*}$ & $20.7 \pm 24.8$ & $84.0(70.5-90.0)$ & 0.075 \\
Pre-op eGFR $\left(\mathrm{mL} / \mathrm{min} / 1.73 \mathrm{~m}^{2}\right)$ & $88.0(78.8-90.0)$ & $65.0(52.5-72.5)$ & 0.397 \\
Age (years) & $67.5(50.3-70.5)$ & 0.607 \\
\hline
\end{tabular}

Data are displayed as median (IQR), apart from * which is expressed as mean \pm SD. Statistically significant results are highlighted in bold

Table 3 Relationship between day 1 post-operative $\mathrm{Mg}^{2+}$ levels and other examined variables

\begin{tabular}{ll}
\hline & Day 1 post-operative $\mathrm{Mg}^{2+}$ \\
\hline Pre-op $\mathrm{Mg}^{2+}$ & $* r=0.561,95 \% \mathrm{CI} 0.352$ to $0.712, p<0.001$ \\
Pre-op adj. $\mathrm{Ca}^{2+}$ & $r=-0.389,95 \% \mathrm{CI}-0.548$ to $-0.201, p<0.001$ \\
Post-op PTH & $r=0.210,95 \% \mathrm{CI} 0.007$ to $0.396, p=0.037$ \\
Post-op adj. $\mathrm{Ca}^{2+}$ & $r=-0.156,95 \% \mathrm{CI}-0.348$ to $0.049, p=0.124$ \\
Pre-op eGFR & $r=-0.148,95 \% \mathrm{CI}-0.341$ to $0.056, p=0.142$ \\
Pre-op PTH & $r=-0.077,95 \% \mathrm{CI}-0.275$ to $0.129, p=0.451$ \\
Age & $r=-0.026,95 \% \mathrm{CI}-0.228$ to $0.178, p=0.798$ \\
\hline
\end{tabular}

The variables are ordered by their strength of correlation with day 1 post-op $\mathrm{Mg}^{2+}$ levels in descending order. Data are displayed as Spearman's (*Pearson's) $r, 95 \% \mathrm{CI}$ and $p . n=99$ in all groups apart from pre-op $\mathrm{Mg}^{2+}(n=57)$

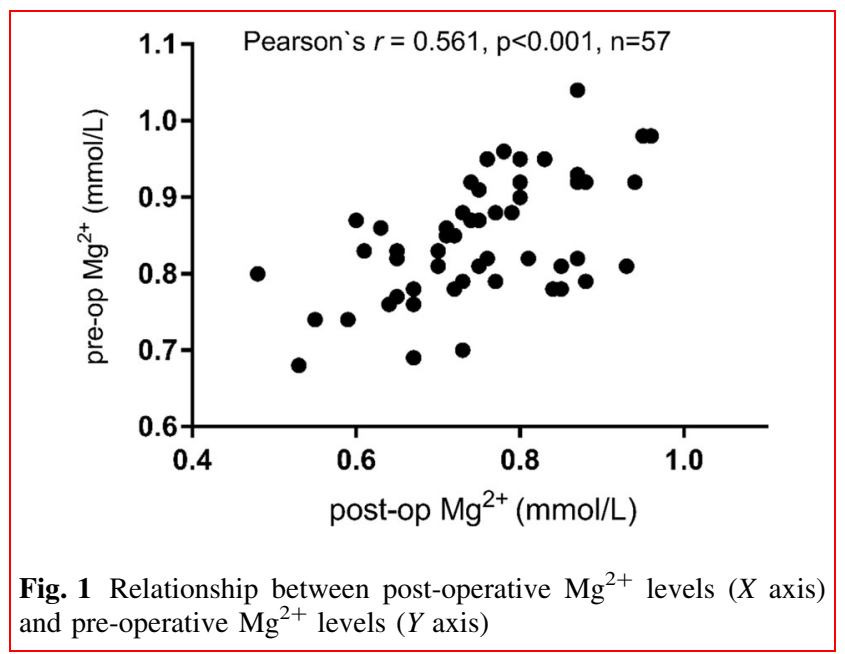

operative PTH levels $(r=0.210,95 \%$ CI $0.007-0.396$, $p=0.037, n=99$ ) (Fig. 3 and Table 3). The relationships between day 1 post-operative $\mathrm{Mg}^{2+}$ and post-operative

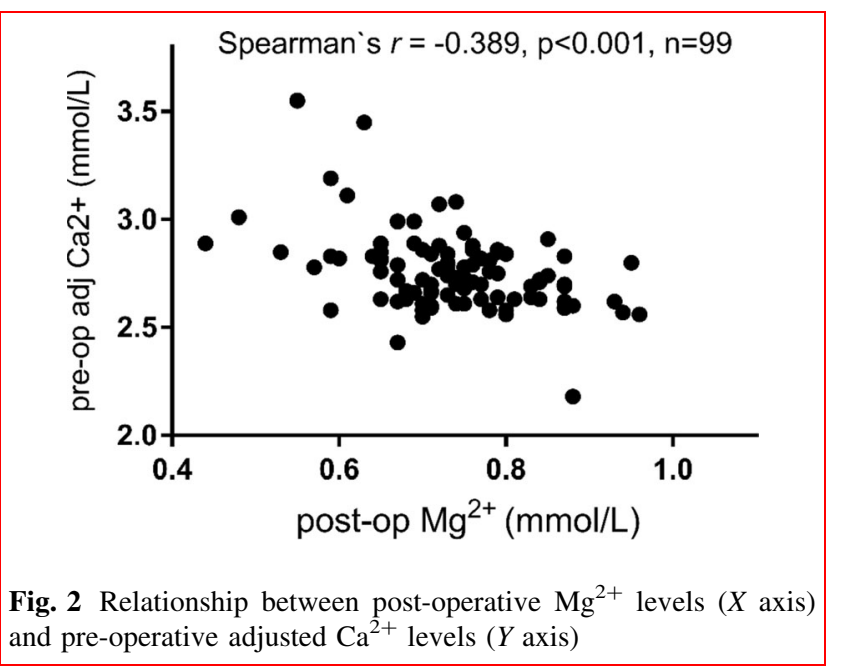

adjusted $\mathrm{Ca}^{2+}$ levels, pre-operative eGFR, pre-operative PTH and age did not reach statistical significance (Table 3). 


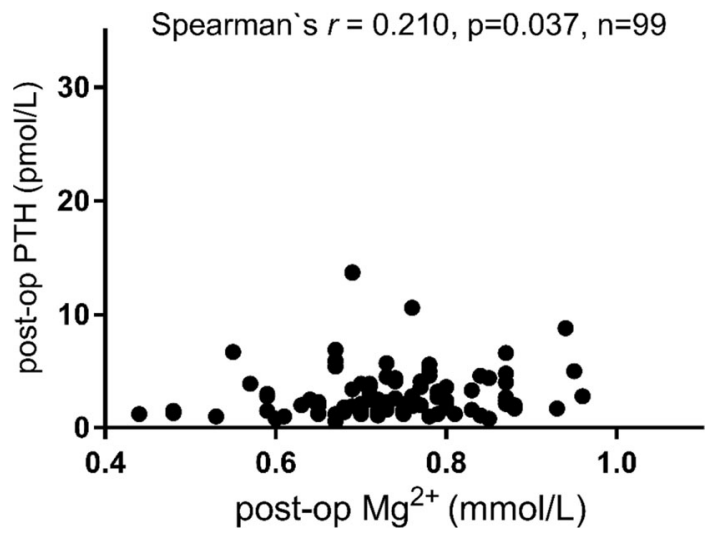

Fig. 3 Relationship between post-operative $\mathrm{Mg}^{2+}$ levels ( $X$ axis) and post-operative PTH levels ( $Y$ axis)

Lastly, no significant association was found between the presence of day 1 post-operative hypomagnesaemia and history of pre-operative bisphosphonate use $\left(X^{2}=3.275\right.$, $p=0.070)$, pre-operative PPI use $\left(X^{2}=0.446, p=0.504\right)$ or diagnosis of osteoporosis $\left(X^{2}=0.334, p=0.563\right)$.

\section{Discussion}

This prospective study has demonstrated that parathyroidectomy for PHPT caused a significant reduction in serum $\mathrm{Mg}^{2+}$ levels and that nearly a third of patients had hypomagnesaemia $(<0.70 \mathrm{mmol} / \mathrm{L})$ on the day after surgery. Three of these had severe hypomagnesaemia $(<0.50 \mathrm{mmol} / \mathrm{L})$. Patients with hypomagnesaemia had lower pre-operative serum $\mathrm{Mg}^{2+}$, higher pre- and postoperative serum adjusted $\mathrm{Ca}^{2+}$ and higher drop in adjusted $\mathrm{Ca}^{2+}$ levels in comparison with those without hypomagnesaemia. Post-operative $\mathrm{Mg}^{2+}$ levels correlated directly with pre-operative $\mathrm{Mg}^{2+}$ levels and inversely with preoperative adjusted $\mathrm{Ca}^{2+}$ levels.

Before the initiation of this study, 3 patients who underwent parathyroidectomy for PHPT in our centre presented with signs and symptoms of severe hypomagnesaemia several days after the surgery. An 85-year-old lady presented with confusion and paraesthesia 5 days after parathyroidectomy. She sustained a right neck of femur fracture due to a fall off her bed after an epileptic seizure. Her serum $\mathrm{Mg}^{2+}$ at that time was recorded at $0.43 \mathrm{mmol} / \mathrm{L}$. She also had mild hypocalcaemia (adj. $\mathrm{Ca}^{2+} 2.05 \mathrm{mmol} / \mathrm{L}$ ) and moderate hyponatraemia $\left(\mathrm{Na}^{+} 128 \mathrm{mmol} / \mathrm{L}\right)$, whilst other investigations including septic screen and CT head were all normal. Her symptoms resolved quickly with correction of electrolyte abnormalities following which she underwent an uneventful hemiarthroplasty for the femur fracture. The second case was a 72-year-old lady who presented with bilateral leg paraesthesia, sensory changes and generalised weakness 8 days after parathyroidectomy. Serum $\mathrm{Mg}^{2+}$ was recorded at $0.40 \mathrm{mmol} / \mathrm{L}$ (adj. $\mathrm{Ca}^{2+}$ mildly elevated at $2.64 \mathrm{mmol} / \mathrm{L}$ ) and her symptoms resolved completely following intravenous $\mathrm{Mg}^{2+}$ replacement. The third patient was an 89-year-old man who presented with confusion 14 days after parathyroidectomy. His confusion resolved completely following correction of severe hypomagnesaemia $(0.50 \mathrm{mmol} / \mathrm{L})$ and mild hypocalcaemia (adj. $\mathrm{Ca}^{2+} 2.05 \mathrm{mmol} / \mathrm{L}$ ). Symptoms observed in these patients are in keeping with severe hypomagnesaemia. Their rapid and complete resolution of symptoms following normalisation of $\mathrm{Mg}^{2+}$ levels together with the absence of other plausible clinical conditions is strongly suggestive of a causal link with the documented severe hypomagnesaemia. Following these clinical incidents, a prospective evaluation of serum $\mathrm{Mg}^{2+}$ levels in patients undergoing parathyroidectomy for PHPT over a period of one year was carried out.

To our knowledge, this is a first study of its kind in parathyroid surgery. A recent study by an Indian group examining pre-operative and day 1 post-operative serum $\mathrm{Ca}^{2+}$ and $\mathrm{Mg}^{2+}$ levels in 50 patients undergoing thyroidectomy for benign or malignant thyroid disease reported that $58 \%$ patients developed post-operative hypocalcaemia, 34\% developed hypomagnesaemia and $30 \%$ developed both conditions [6]. In another study, Wilson et al. [7] measured serum $\mathrm{Mg}^{2+}$ and $\mathrm{Ca}^{2+}$ levels in the immediate post-operative period in 50 patients who underwent total thyroidectomy and found that $34 / 50(68 \%)$ patients had hypocalcaemia and 36/50 (72\%) experienced hypomagnesaemia. This has been attributed at least partly to transient hypoparathyroidism. However, DemeesterMirkine et al. [8] found transient falls in serum $\mathrm{Ca}^{2+}$, $\mathrm{Mg}^{2+}, \mathrm{Na}^{+}, \mathrm{K}^{+}, \mathrm{Cl}^{-}$, phosphorus, osmolarity and total protein in both control surgical patients $(n=104)$ and thyroidectomy patients $(n=135)$ and concluded that haemodilution plays a role.

Hypomagnesaemia results from either impaired intestinal absorption or increased gastrointestinal losses (malnutrition, malabsorption, chronic diarrhoea), rapid $\mathrm{Mg}^{2+}$ redistribution (hungry bone syndrome, insulin treatment, acute pancreatitis) or, most commonly, due to factors influencing renal $\mathrm{Mg}^{2+}$ handling (examples include hereditary genetic conditions, medications and endocrine conditions such as PHPT, hyperthyroidism or hyperaldosteronism) [4]. Magnesium levels also drop after bowel preparation or blood transfusions, administration of catecholamines or due to extracellular volume expansion [1,4], most of which are associated with a number of different operations. Following parathyroidectomy and the associated steep decline in serum PTH, changes in bone and mineral metabolism occur rapidly, resulting in 
normalisation or lowering of serum $\mathrm{Ca}^{2+}$ levels. Hungry bone syndrome represents a situation of accelerated net bone formation [9]. The rapid remineralisation of the demineralised skeleton results in hypocalcaemia, hypophosphataemia and hypomagnesaemia [1, 4]. Given the unlikely contribution of factors such as significant volume expansion, catecholamine infusion and blood transfusion in parathyroid surgery, and the role of bone remineralisation, the aetiology of the mild day 1 post-operative hypomagnesaemia observed in our patients is likely to be due to a combination of hungry bone syndrome and hypoparathyroidism.

Hypomagnesaemia is a common electrolyte disturbance in hospital settings, especially in the critically ill with reported presence in $20-60 \%$ of patients entering intensive care $[10,11]$. Whilst it is commonly accepted that cases of severe or symptomatic hypomagnesaemia should be treated, the treatment of mild and asymptomatic hypomagnesaemia is more controversial [4]. There are data available to suggest that hospitalised patients with hypomagnesaemia have worse clinical outcomes in comparison with patients with normal $\mathrm{Mg}^{2+}$ levels; however, no controlled trials have assessed whether $\mathrm{Mg}^{2+}$ supplementation improves these outcomes [4].

In this study, only $7 / 99$ (7.1\%) patients had day 1 postoperative hypocalcaemia. The occurrence of hypomagnesaemia without concomitant hypocalcaemia is interesting and could be linked to the fall in calcium from a high preoperative level in association with the shift of calcium and magnesium into the bones as seen in hungry bone syndrome [12]. We have, however, detected higher drop in adj. $\mathrm{Ca}^{2+}$ levels following surgery in patients with hypomagnesaemia when compared to those with day 1 post-operative normomagnesaemia. These observations are consistent with the expected net shift of calcium and magnesium into the bones after parathyroid surgery. Sutton et al. examined pre-operative serum $\mathrm{Mg}^{2+}$ levels in 73 patients with PHPT and reported that 5/73 (6.8\%) had hypomagnesaemia [13]. King et al. studied 48 patients with PHPT and found preoperative hypomagnesaemia in $9 / 48(18.8 \%)$ of patients [14]. They also comment that a significant and sustained post-operative hypomagnesaemia occurred only in patients with generalised bone disease [14]. There are also other reports in the literature of profound hypomagnesaemia after parathyroidectomy for PHPT in patients with generalised bone disease $[15,16]$. In our study, 2/57 (3.5\%) patients had mild pre-operative hypomagnesaemia and we did not detect any differences in serum $\mathrm{Mg}^{2+}$ levels between those with and without osteoporosis, although admittedly our numbers are small.

Our work has several limitations. Magnesium levels are missing for a significant proportion of patients operated in this time period. Routine $\mathrm{Mg}^{2+}$ checks were only being introduced in the unit and were not fully embedded in clinical practice. It is possible that there is a selection bias. However, we think this is unlikely as the clinical team involved were not specifically looking for magnesium deficiency prior to surgery for PHPT. Firstly, we only measured day 1 post-operative $\mathrm{Mg}^{2+}$ levels as patients only stay in hospital for a short period after parathyroidectomy. It would be interesting to measure serial $\mathrm{Mg}^{2+}$ readings at different time points after parathyroidectomy to establish the temporal relationship of $\mathrm{Mg}^{2+}$ metabolism and thus inform the practice for the future. Secondly, we are unable to assess the effect of vitamin $\mathrm{D}$ on the changes in magnesium homeostasis as we did not collect data on vitamin D status in our patients. Our practice in relation to management of PHPT, however, follows the Endocrine Society recommendations [5] and we routinely measure vitamin D status at the diagnostic evaluation of this condition. Patients with vitamin D deficiency (serum $25(\mathrm{OH}) \mathrm{D}<50$ $\mathrm{nmol} / \mathrm{L}$ ) get treatment before surgery. It is possible that there is a surgeon effect. However, this is unlikely as only two surgeons were involved either directly performing the surgery or supervising trainee surgeons. Both these surgeons have encountered this problem during the study period and have similar success rates.

In our centre, $\mathrm{Mg}^{2+}$ levels are now routinely measured in patients with PHPT before and immediately after parathyroidectomy. Any mild hypomagnesaemia is managed with a short course of oral $\mathrm{Mg}^{2+}$ supplementation followed by reassessment of $\mathrm{Mg}^{2+}$ levels. The relatively low cost of serum magnesium measurement (1.34 GBP/test at authors' institution at the time of manuscript preparation) and the hypomagnesaemia treatment make this possible without a significant increase in health care costs. Our management of hypomagnesaemia after parathyroidectomy is, however, based on the extrapolation from treatment recommendations of hypomagnesaemia in other settings, and its effectiveness is as yet not known. It is also not clear whether the treatment of mild hypomagnesaemia is definitively indicated as it may well be transient and may resolve spontaneously for the reasons discussed above. However, based on the three patients who had significant morbidity due to hypomagnesaemia and the relatively low costs of measuring serum magnesium (1.34 GBP/test at authors' institution at the time of manuscript preparation) and treating hypomagnesaemia, we would recommend other centres to consider testing and treating for hypomagnaesemia. Clearly, more work needs to be done to establish the clinical importance of mild hypomagnesaemia in these clinical settings and, if indicated, to devise optimal treatment protocols and evaluate strategies to reduce risk of hypomagnesaemia by conducting studies in larger numbers of patients. 


\section{Compliance with ethical standards}

Conflict of interest PN has served on speaker panels for NovoNordisk and on advisory panels for Sanofi and received travel grants from Eli Lilly and Sanofi. AFL, CBBL and SPB declare that they have no conflict of interest.

Open Access This article is licensed under a Creative Commons Attribution 4.0 International License, which permits use, sharing, adaptation, distribution and reproduction in any medium or format, as long as you give appropriate credit to the original author(s) and the source, provide a link to the Creative Commons licence, and indicate if changes were made. The images or other third party material in this article are included in the article's Creative Commons licence, unless indicated otherwise in a credit line to the material. If material is not included in the article's Creative Commons licence and your intended use is not permitted by statutory regulation or exceeds the permitted use, you will need to obtain permission directly from the copyright holder. To view a copy of this licence, visit http://creativecommons. org/licenses/by/4.0/.

\section{References}

1. Bringhurst FR, Demay MB, Kronenberg HM (2016) Hormones and disorders of mineral metabolism. In: Melmed S, Pollonsky KS, Reed Larsen P, Kronenberg HM (eds) Williams textbook of endocrinology. Elsevier, Philadelphia, pp 1254-1322

2. Boonstra CE, Jackson CE (1971) Serum calcium survey for hyperparathyroidism: results in 50,000 clinic patients. Am J Clin Pathol 55:523-526

3. Wermers RA, Khosla S, Atkinson EJ et al (2006) Incidence of primary hyperparathyroidism in Rochester, Minnesota, 1993-2001: an update on the changing epidemiology of the disease. J Bone Miner Res 21:171-177

4. Martin KJ, Gonzalez EA, Slatopolsky E (2009) Clinical consequences and management of hypomagnesemia. J Am Soc Nephrol 20:2291-2295
5. Bilezikian JP, Brandi ML, Eastell R et al (2014) Guidelines for the management of asymptomatic primary hyperparathyroidism: summary statement from the Fourth International Workshop. J Clin Endocrinol Metab 99:3561-3569

6. Chincholikar SP, Ambiger S (2018) Association of hypomagnesemia with hypocalcemia after thyroidectomy. Indian J Endocrinol Metab 22:656-660

7. Wilson RB, Erskine C, Crowe PJ (2000) Hypomagnesemia and hypocalcemia after thyroidectomy: prospective study. World J Surg 24:722-726. https://doi.org/10.1007/s002689910116

8. Demeester-Mirkine N, Hooghe L, Van Geertruyden J, De Maertelaer V (1992) Hypocalcemia after thyroidectomy. Arch Surg 127:854-858

9. Brasier AR, Nussbaum SR (1988) Hungry bone syndrome: clinical and biochemical predictors of its occurrence after parathyroid surgery. Am J Med 84:654-660

10. Reinhart RA, Desbiens NA (1985) Hypomagnesemia in patients entering the ICU. Crit Care Med 13:506-507

11. Ryzen E, Wagers PW, Singer FR, Rude RK (1985) Magnesium deficiency in a medical ICU population. Crit Care Med 13:19-21

12. Witteveen JE, van Thiel S, Romijn JA, Hamdy NA (2013) Hungry bone syndrome: still a challenge in the post-operative management of primary hyperparathyroidism: a systematic review of the literature. Eur J Endocrinol 168:R45-R53

13. Sutton RA (1970) Plasma magnesium concentration in primary hyperparathyroidism. Br Med J 1:529-533

14. King RG, Stanbury SW (1970) Magnesium metabolism in primary hyperparathyroidism. Clin Sci 39:281-303

15. Jones CT, Sellwood RA, Evanson JM (1973) Symptomatic hypomagnesaemia after parathyroidectomy. Br Med J 3:391-392

16. Tambyah PA, Rauff A, Lee KO (1990) Persistent hypomagnesaemia following parathyroid surgery, hypermagnesuria as a possible cause. Ann Acad Med Singapore 19:536-539

Publisher's Note Springer Nature remains neutral with regard to jurisdictional claims in published maps and institutional affiliations. 